Published in final edited form as:

Chembiochem. 2018 September 04; 19(17): 1827-1833. doi:10.1002/cbic.201800214.

\title{
Mammalian Cells Engineered to Produce Novel Steroids
}

\author{
Emma S. Spady a,b,c, Thomas P. Wyche ${ }^{d}$, Nathanael J. Rollins ${ }^{a, c}$, Jon Clardy $^{d}$, Jeffrey C. \\ Way ${ }^{a, c}$, and Pamela A. Silver ${ }^{a, c},{ }^{*}$ \\ [a]Department of Systems Biology, Harvard Medical School - Boston, MA 02115, United States \\ [b]Laboratory of Systems Pharmacology, Harvard University - Boston, MA 02115, United States \\ [c]Wyss Institute for Biologically Inspired Engineering, Harvard University - Boston, MA 02115, \\ United States \\ [d]Department of Biological Chemistry and Molecular Pharmacology, Harvard Medical School - \\ Boston, MA 02115, United States
}

\begin{abstract}
Steroids can be difficult to modify via traditional organic synthesis methods, but many enzymes regio- and stereo-selectively process a wide variety of steroid substrates. We tested whether steroid-modifying enzymes could make novel steroids from non-native substrates. Numerous genes encoding steroid-modifying enzymes, including some bacterial enzymes, were expressed in mammalian cells by transient transfection and found to be active. We made three unusual steroids by stable expression in HEK293 cells of the 7a-hydroxylase CYP7B1, which was selected because of high native product yield. These cells made 7a,17a-dihydroxypregnenolone and $7 \beta$, 17a-dihydroxypregnenolone from 17a-hydroxypregnenolone, and produced 11a, 16adihydroxyprogesterone from 16a-hydroxyprogesterone. The latter two products resulted from previously unobserved CYP7B1 hydroxylation sites. A Rosetta docking model of CYP7B1 suggested that these substrates' D-ring hydroxylations may prevent them from binding in the same way as the native substrate, bringing different carbons near the active ferryl oxygen. This new approach could use other enzymes and substrates to produce many novel steroids for drug candidate testing.
\end{abstract}

\section{Keywords}

Steroids; Biosynthesis; Synthetic Biology; Cytochromes

Steroids represent an important class of therapeutically useful molecules, but they have significant dose-limiting side effects. Steroid hormone analogs take advantage of the wide-

\footnotetext{
"Corresponding Author: pamela_silver@hms.harvard.edu.

Current Affiliations

Thomas P. Wyche: Merck \& Co., Inc., Cambridge, MA 02141, United States.

Supporting Information Available: Yield tables for all enzymes, descriptions of conditions to improve yield, supplementary methods, and NMR shifts, assignments, and spectra (PDF). CYP7B1 substrate binding predictions from Rosetta (ZIP). Intermediate structures used in CYP7B1 modeling (ZIP). This material is available free of charge via the Internet.

The authors declare no competing financial interest.
} 
ranging effects of their endogenous counterparts, such as immunosuppression and increased bone density, and are used to treat conditions ranging from arthritis to anemia.

Unfortunately, steroid receptors alter global responses, so steroid drugs have severe side effects. These include diabetes and osteoporosis for glucocorticoids and masculinizing effects for androgens. ${ }^{[1-3]}$ Steroids are active at bloodstream concentrations in the nanomolar range and readily cross cell membranes. ${ }^{[4,5]}$ New combinations of modifications around the central steroid scaffold could improve binding affinity, pharmacokinetic properties, and receptor specificity. ${ }^{[6]}$

Steroids must be modified stereo- and regio-specifically to result in useful drugs. Steroid receptor binding pockets are sensitive to minor modifications; a single hydroxylation or methylation can cause a steroid to bind a different receptor, dramatically changing its biological effects. ${ }^{[6]}$ Due to its lack of activated carbons, the steroid ring structure is difficult to modify while preserving its integrity. ${ }^{[7]}$ Traditional chemical processes for steroid modifications are elaborate and frequently less selective than their biological counterparts, to the extent that wild-type fungi are used as industrial biocatalysts. ${ }^{[7-9]}$

Biosynthesis can provide an alternative source of novel steroid therapeutics. The enzymes involved in steroid hormone synthesis modify a large variety of substrates, but still perform regio- and stereoselective reactions. ${ }^{[10]}$ In principle, these enzymes could accept a wide variety of synthetic steroid substrates and modify them to create novel products. A single enzymatic step could replace a long organic synthesis, and thus allow for extensive exploration of the steroid drug biochemical space. Exogenous expression of steroid enzymes has already been used to produce complicated steroids intracellularly in yeast and mammalian cells, with glucocorticoids being of particular interest. ${ }^{[11,12]}$ However, intentional biosynthesis of chemically novel steroid products using engineered mammalian cells has not been deeply explored.

Here we report the synthesis of novel steroids by expressing various steroid-modifying enzymes in mammalian cells and providing them with non-native substrates. We isolated three steroids by expressing the steroid 7a-hydroxylase CYP7B1, two of which arose from the enzyme's previously unknown ability to $11 \alpha$ - and $7 \beta$-hydroxylate substrates. This approach could be used to synthesize a wide variety of steroids for which traditional organic synthesis is not feasible.

Our strategy for novel steroid synthesis is to express genes encoding steroid-modifying enzymes in mammalian cells, and then supply the cells with non-native substrates that will result in novel products (Figure 1). To identify candidates, we expressed a panel of enzymes in mammalian cells and confirmed their function on native substrates. We then selected one of the best-performing enzymes, CYP7B1, and chose non-native substrates that would result in novel products, assuming that the enzyme modifies the substrates selectively. We isolated the products from the enzyme acting on the alternative substrate, and confirmed the steroids' structures via NMR. Notably, we observed the 7a-hydroxylase CYP7B1 performing significant amounts of $11 \alpha$ - and $7 \beta$-hydroxylation on the alternative substrates. We explained how these unexpected products may have arisen with a Rosetta docking model for the substrates in the enzyme's binding pocket. 
Mammalian cells were used in this work because of several unique properties. Firstly, most of the enzymes tested were human, and cytochrome P450s can be difficult to express in heterologous hosts. ${ }^{[12,13]}$ Mammalian cells also enable these enzymes to access cholesterol when required as a substrate. As there is no lipopolysaccharide in this system, any steroids in tissue culture supernatant could be tested rapidly on other mammalian cell lines without purification. While mammalian cells are unlikely to achieve the yields of yeast or bacterial cells, steroids are very potent drugs, and thus can be studied even in small quantities. ${ }^{[14,15]}$

Seventeen steroid-modifying enzymes were selected for expression in the human cell line HEK293. The enzymes were identified based on their gene sequence availability and the diverse reactions they catalyze (Table S1). Most of these enzymes are cytochrome P450s, and many are hydroxylases; the group also contains dehydrogenases, a methyltransferase, and a Baeyer-Villiger monooxygenase. Mammalian steroid-modifying enzymes are generally associated with the mitochondria or endoplasmic reticulum and may have signal sequences targeting them to these organelles; these sequences were retained. Bacterial enzymes were expressed without signal sequences and presumably localized to the cell cytoplasm. The HEK293 cell line was chosen because of its hardiness and ease of transfection.

Expression constructs encoding each enzyme were transfected into HEK293 cells, and activity of each enzyme was tested on a native substrate and assayed via LC-MS. Negative enzyme activity controls consisted of transfecting the same plasmid backbone, but with a fluorescent reporter protein under the constitutive promoter. Cells were incubated for two days with a $40 \mu \mathrm{M}$ solution of a native substrate for the relevant enzyme. The substrate concentration was chosen because of the low solubility of the less-hydroxylated steroids in media. ${ }^{[16]}$ Lipids were extracted from the spent cells and media and measured by LC-MS. ${ }^{[17,18]}$ The yield per milliliter of spent media was determined for each product when a standard was available.

Of the enzymes tested, the human 7a-hydroxylase CYP7B1 and the Pseudomonas cyclopentadecanone monooxygenase $\mathrm{CpdB}$ had the highest yields. CYP7B1 produced 1.4 $\mu \mathrm{g}$ of 7a-hydroxypregnenolone per $\mathrm{mL}$ (2) from a $12.7 \mu \mathrm{gL}^{-1}$ pregnenolone solution (1) (Scheme 1A). CpdB made $2.6 \mu \mathrm{g}$ of testololactone per $\mathrm{mL}(\mathbf{1 0})$ from an $11.5 \mu \mathrm{g} \mathrm{mL}^{-1}$ solution of androstenedione (9) (Scheme S1). Eight other steroid-modifying enzyme plasmids resulted in significantly more product than the fluorescent protein control when transfected (Table S1). These included two more bacterial enzymes, $\delta^{1}$-KSTD2 and CYP154C3 (Scheme S1). Enzymes that failed may have done so because of poor gene expression, but rather than troubleshooting, we focused on those enzymes that worked well immediately. CYP7B1 was pursued further, as it is a well-studied human enzyme. ${ }^{[19,20]}$ The high 7a-pregnenolone (2) yield implied CYP7B1 had a good chance of processing alternative substrates into detectable quantities of novel steroids.

The CYP7B1-expressing cells' yield of 2 improved under different expression conditions. This ensured that the enzyme's action on alternative substrates would result in sufficient product for structure determination. The CYP7B1 electron transfer partner, cytochrome P450 oxidoreductase (POR), was expressed alongside CYP7B1 to prevent POR from 
limiting steroid hydroxylation. A modest $34 \%$ increase in 2 yield was achieved by transfecting CYP7B1 plasmid into stable POR-expressing HEK293 cells (Figure S1A). A CYP7B1-expressing stable pool was constructed by puromycin selection to enable longer exposure of cells to substrate. These cells could be plated at low density and grown to confluency in the same media, allowing for eight days of incubation with substrate instead of 48 hours. HEK293 cells were transfected with the CYP7B1 vector used previously, and were selected on puromycin. This stable pool improved 2 yield by $229 \%$, to $4.6 \mu \mathrm{g} \mathrm{mL}$ (Figure S1A). The CYP7B1-expressing stable pool was used in subsequent steroid syntheses, and the POR stable pool was not used.

Stable CYP7B1-expressing cells were incubated with two alternative substrates that we predicted would result in novel products. We anticipated that CYP7B1 would convert 17ahydroxypregnenolone (3) to 7a,17a-dihydroxypregnenolone (4) (Scheme 1B). Similarly, CYP7B1 was expected to hydroxylate $16 a$-hydroxyprogesterone (7) to produce $7 a, 16 a-$ dihydroxyprogesterone (6) (Scheme 1C). The CYP7B1 stable pool cell line was plated at low density and cultivated in the presence of a $40 \mu \mathrm{M}$ alternative substrate solution for eight days. This corresponds to a $13.3 \mu \mathrm{g} \mathrm{mL}-1$ solution of $\mathbf{3}$ and a $13.2 \mu \mathrm{g} \mathrm{mL} \mathrm{m}^{-1}$ solution of 7 . Lipids were extracted and detected by LC-MS as in the native substrate experiments. The lipids were compared to those from identically treated negative control stable pool cells, which expressed GFP instead of an enzyme. The desired hydroxylation product peaks were identified by having the correct mass and only being present with CYP7B1 expression. This separated the desired steroids from any hydroxylated isomers due to spontaneous degradation.

Peaks with masses corresponding to hydroxylation of the alternative substrates were detected exclusively in CYP7B1-expressing cells. CYP7B1 cells provided with alternative substrate 3 yielded two dihydroxypregnenolone peaks not present in the control (Figure 2A). As dihydroxypregnenolones lose water during ESI-MS, the product peaks contained $\mathrm{m} / \mathrm{z}=$ $331.2269,313.2162$, and 295.2057, corresponding to $\left[\mathrm{M}+\mathrm{H}-\mathrm{H}_{2} \mathrm{O}\right]^{+},\left[\mathrm{M}+\mathrm{H}-2 \mathrm{H}_{2} \mathrm{O}\right]^{+}$, and $[\mathrm{M}$ $\left.+\mathrm{H}-3 \mathrm{H}_{2} \mathrm{O}\right]^{+}$ions (Supplementary Results). The later, high signal molecule 4 eluted at 2.7 minutes, and the earlier, low signal molecule 5 eluted at 2.3 minutes. $0.7 \mathrm{mg}$ of $\mathbf{4}$ and $0.4 \mathrm{mg}$ of 5 were subsequently purified, implying a yield of $1.6 \mu \mathrm{gL}^{-1}$ and $0.91 \mu \mathrm{g} \mathrm{mL} L^{-1}$, respectively.

Analysis of 1D and 2D NMR data (gCOSY, gHSQC, gHMBC, ROESY, and TOCSY) allowed for structure determination of dihydroxypregnenolones $\mathbf{4}$ and $\mathbf{5}$, corresponding to an expected 7a-hydroxylated product and an unexpected $7 \beta$-hydroxylated product (Scheme 1B, Table S2). COSY interactions between the hydrogen at C- $6\left(\delta_{\mathrm{H}} 5.57,5.28\right)$ and a hydroxyladjacent hydrogen $\left(\delta_{\mathrm{H}} 3.8,3.79\right)$ in $\mathbf{4}$ and $\mathbf{5}$, respectively, revealed that both products were 7hydroxylated. The $\mathrm{C}-7$ hydroxyl stereochemistry was determined by comparing the isomers to reference NMR for $7 a$-hydroxypregnenolone $\left(\delta_{\mathrm{C}-7} 65.20\right)$ and $7 \beta$-hydroxypregnenolone $\left(\delta_{\mathrm{C}-7} 73.14\right) \cdot{ }^{[21,22]}$ Compound $4\left(\delta_{\mathrm{C}-7} 65.95\right)$ is therefore $7 a, 17 a$-dihydroxypregnenolone while $5\left(\delta_{\mathrm{C}-7} 73.99\right)$ is $7 \beta, 17 a$-dihydroxypregnenolone.

The CYP7B1 stable pool cells provided with alternative substrate 7 exhibited a single dihydroxyprogesterone product peak (Figure 2B). Dihydroxyprogesterones do not lose water 
as easily in ESI-MS, so the product peak was exclusively $\mathrm{m} / \mathrm{z}=347.2222$, corresponding to the $[\mathrm{M}+\mathrm{H}]^{+}$ion (Supplementary Results). A single isomer 8 with this $\mathrm{m} / \mathrm{z}$ eluted at 2.05 minutes, and was absent in the negative control lipids. $2.2 \mathrm{mg}$ of 8 were eventually purified from tissue culture, with a yield of $6.9 \mu \mathrm{g} \mathrm{mL} \mathrm{m}^{-1}$.

Compound 8 , the single dihydroxyprogesterone product, was determined to be 11a,16adihydroxyprogesterone after analysis of 1D and 2D NMR data (Scheme 1C, Table S2). No other masses that could correspond to the expected product 6 were detected. The newly hydroxylated carbon $\left(\delta_{\mathrm{C}} 68.88, \delta_{\mathrm{H}} 3.95\right)$ was identified by locating its methylene neighbor $\left(\delta_{\mathrm{C}} 50.89, \delta_{\mathrm{H}} 1.63,2.24\right)$, with which it has a strong COSY correlation. This neighboring carbon has an $\mathrm{HMBC}$ with hydrogens at $\mathrm{C}-17\left(\delta_{\mathrm{H}} 2.58\right)$ and $\mathrm{C}-18\left(\delta_{\mathrm{H}} 0.70\right)$. This placed the neighboring carbon at $\mathrm{C}-12$, as the D-ring hydroxyl had already been assigned and other locations were too far from C-17 and C-18. Therefore the CYP7B1 hydroxylation was at $\mathrm{C}-11$. The $\mathrm{C}-11$ hydroxyl stereochemistry was found through ROESY interactions. The hydrogen at $\mathrm{C}-11\left(\delta_{\mathrm{H}} 3.95\right)$ interacts with hydrogens at $\mathrm{C}-18\left(\delta_{\mathrm{H}} 0.70\right)$ and $\mathrm{C}-19\left(\delta_{\mathrm{H}} 1.35\right)$, indicating that it is above the steroid ring plane. The hydroxyl at $\mathrm{C}-11$ must face the opposite direction, and thus is an 11a-hydroxyl.

The macromolecular modeling software Rosetta was used to model native substrate $\mathbf{1}$ and alternative substrates $\mathbf{3}$ and $\mathbf{7}$ binding to CYP7B1 to better understand how the unexpected products $\mathbf{5}$ and $\mathbf{8}$ could arise. Predictive modeling of cytochrome P450 reaction sites is difficult; ${ }^{[23]}$ our models instead aim to identify why we observe different reactions for Dring hydroxylated substrates than for the native substrate. ${ }^{[20]}$ As there are no CYP7B1 crystal structures, we used Rosetta to generate structure models before docking the substrates. Comparative modeling in Rosetta predicts protein structure based on solved structures of homologs, from which it generates candidate structures. ${ }^{[24]}$ The structure of CYP7A1, which is $41 \%$ sequence identical to CYP7B1 with 95\% coverage, has been solved and served as a starting point for comparative modeling. ${ }^{[25]}$ Binding modes were generated and those with the lowest energy were identified by Rosetta's $\Delta \mathrm{G}$ analog score, resulting in multiple lowest energy modes with inseparable energy scores for each substrate. The reactive binding mode was found among the best predictions by proximity of observed hydroxylation position to the ferryl oxygen (see Experimental Section). These were analyzed as the best hypotheses for how CYP7B1 catalyzes 7a-, 7 $\beta$ - and 11a-hydroxylation on the steroids studied (Figure 3).

These structure models suggest that unexpected CYP7B1 activities on $\mathbf{3}$ and $\mathbf{7}$ arise from these substrates shifting out of a tight pocket and tilting relative to the reactive ferryl oxygen. Cytochrome P450s typically hydroxylate the carbon closest to the ferryl oxygen; the mechanism does not require any activation of the substrate, though the transient carbanion intermediate formed favors carbons adjacent to double bonds. ${ }^{[26]}$ As C-7 is adjacent to a double bond in native substrate $\mathbf{1}$ and the alternative substrate $\mathbf{3}$, it is a particularly good hydroxylation site, and thus observed in their products (Figure 3BC). However, 3's 17ahydroxyl does not permit it to occupy the same binding position as $\mathbf{1}$ in our model. The hydroxyl forces 3 into a wider channel to the left in the figure, where the steroid can tilt to result 7 $\beta$-hydroxylation (Figure 3D). 7's 16a-hydroxylation would also result in a steric 
clash, which implies it will also shift out of 1's binding pocket. The severity of this clash may drive 7 to rotate dramatically, resulting in the observed 11a-hydroxylation (Figure 3E).

Overall, the hydroxyls' steric clashes appear to drive steroid positioning more than their potential for hydrogen bonding. The D-ring hydroxyls of $\mathbf{3}$ and $\mathbf{7}$ do not form hydrogen bonds in any of the model structures, but nevertheless change these substrates' binding modes. The side view of CYP7Bl's native substrate, pregnenolone (1), shows its tight fit in a hydrophobic binding pocket with little room beneath the D-ring (Figure 3F). This fit may hold the substrate steady to ensure hydroxylation exclusively at position $7 \mathrm{a}$. Functional groups at C-16 and C-17, such as those in $\mathbf{3}$ and $\mathbf{7}$, can disrupt this fit to cause the observed loss of reaction specificity.

We made the three steroids $\mathbf{4}, \mathbf{5}$, and $\mathbf{8}$ by expressing CYP7B1 in mammalian cells and providing it with non-native substrates 3 and 7.5 and 8 were the result of $7 \beta$ - and $11 a-$ hydroxylations, respectively, though CYP7B1 was thought to primarily perform $7 \mathrm{a}$ hydroxylation. Docking substrates $\mathbf{3}$ and $\mathbf{7}$ into the enzyme active site suggests that these unexpected reactions arise from the substrates' D-ring hydroxylations pushing them into a tilted orientation. This work represents a proof of concept in using genetically engineered mammalian cells to produce novel steroids, and more broadly in using mammalian cells to produce novel small molecules. Our overall method can take advantage of inexpensive gene synthesis, diverse steroid-modifying enzymes, and mammalian cells' unique properties to quickly create steroids that are compatible with direct biological testing.

Steroids $\mathbf{4}$ and $\mathbf{5}$ are novel molecules, but $\mathbf{8}$ has a straightforward organic synthesis. Nevertheless, $\mathbf{8}$ 's chemical properties are not published; no NMR structural data were released when it was initially isolated. ${ }^{[27]} \mathbf{4}$ and 5 would have been difficult to produce via established methods. Both have been tentatively identified in mixtures of microbial steroid hydroxylation products, but no NMR data is available. ${ }^{[28,29]}$ Selective $7 \beta$-hydroxylation of pregnenolones is possible with organic methods, but syntheses that directly favor 7ahydroxylation do not appear possible. ${ }^{[30]}$ Nevertheless, C-7 is a relatively easy carbon to chemically oxidize, as it is adjacent to a double bond. ${ }^{[31]}$ While microbial pregnenolone $7 \mathrm{a}$ hydroxylation has been described, the organisms make a mixture of products, including non-7-hydroxylated steroids, and the enzymes have not been identified. ${ }^{[32,21,33]}$ Hence our method for 7-hydroxylation fills a gap in steroid biosynthetic methods.

We observed unprecedented amounts of 11a-hydroxylated and $7 \beta$-hydroxylated products from CYP7B1. Prior to this work, CYP7B1 only performed 7a-hydroxylation, $6 a-$ hydroxylation, or $7 \beta$-hydroxylation, depending on the substrate. ${ }^{[34]}$ The lattermost product is minor, when observed at all; it comprised just $1 \%$ of the hydroxysteroid product from CYP7B1 action on DHEA. ${ }^{[35]}$ In comparison, $\mathbf{5}$ was $36 \%$ of the total product isolated from CYP7B1 acting on 3. 11a-hydroxylation by CYP7B1 had never been observed until we isolated $\mathbf{8}$. These reactions demonstrate that even well-studied cytochrome P450s may process new substrates in unexpected ways; one cannot assume which isomers these enzymes produce based only on the available literature. 
Our approach reveals that novel steroids can be generated by combining elements from the human metabolic repertoire. CYP7B1 is a human enzyme; its murine homolog is expressed primarily in the brain and at low levels in the liver. ${ }^{[36]}$ Its $7 a$-hydroxylated steroid products are poorly understood, but improve memory in aged, memory-impaired mice. ${ }^{[34,37]}$ While 7 is not present in the human body, $\mathbf{3}$ is an intermediate formed by CYP17A1 in the adrenal cortex and gonads. ${ }^{[38]}$ However, human CYP17A1 preferentially processes $\mathbf{3}$ further into dehydroepiandrosterone. ${ }^{[39]}$ Though the enzyme dissociates from the steroid after hydroxylation, relatively little $\mathbf{3}$ can escape into other tissues before CYP17A1 acts again. ${ }^{[40]}$ While CYP7B1 likely does not encounter $\mathbf{3}$ in nature, in our system the enzyme is capable of processing this substrate into novel products $\mathbf{4}$ and $\mathbf{5}$.

Here, we engineered mammalian cells to produce previously uncharacterized drug-like small molecules. Numerous protein drugs are already made in mammalian cells, typically due to species-specific post-translational modifications such as N-linked glycosylation. Mammalian cells and mammal-based cell-free systems have been engineered to make steroids, but these were only used to study the biosynthetic pathways of known molecules. ${ }^{[11,41]}$ Engineered steroid biosynthesis, even in microbes, has been used to make known steroids; novel steroids are typically detected spontaneously from unmodified cells. ${ }^{[9,12,32,42]}$ Many novel molecules could be made with engineered cells expressing steroid-modifying enzymes, making more steroids accessible for biological testing. Our in vivo system could be modified to access all parts of the steroid ring system, unlike current organic synthesis methods. This work therefore forms a basis for directed biosynthesis of novel steroids.

\section{Experimental Section}

\section{Plasmids.}

The CYP7B1-containing plasmid had a pcDNA3.1 backbone, a CMV promoter driving intron-free CYP7B1 and puromyin resistance. This pcDNA3.1 backbone from Invitrogen includes a pUC origin and ampicillin resistance to enable maintenance in Escherichia coli. The human CYP7B1 isoform 1 cDNA sequence was from the NCBI CCDS database number 6180.1. The negative control plasmid was identical to the CYP7B1 plasmid, but contained GFP in place of CYP7B1. This codon-optimized GFP sequence was originally from the pSF-CMV-Ub-daGFP plasmid (Oxford Genetics). A list of all steroid-modifying enzymes used in similar plasmids can be found in Table S1. Plasmids were constructed using Gibson assembly to insert IDT gBlocks containing the gene of interest into PCR-amplified plasmid backbones, which were then transformed into chemically-competent $E$. coli K12. Plasmids were prepared using the Qiagen PlasmidPlus MidiPrep or MaxiPrep kit.

\section{Protein Expression in Mammalian Cells.}

HEK293 cells (ATCC) were grown in DMEM (Invitrogen) with 10\% FBS (Gibco) and penicillin-streptomycin (Gibco). Cells were transfected with $31.5 \mu \mathrm{g}$ of plasmid DNA per well in 6-well plates using the Lipofectamine 3000 kit (Thermo Fisher). Media was replaced after six hours with fresh media containing $40 \mu \mathrm{M}$ steroid substrate. For concentrations of each substrate in $\mathrm{ng} \mathrm{mL} \mathrm{m}^{-1}$, refer to Table S1. Cells were incubated for 48 hours, after which the negative controls were checked for fluorescence, indicating acceptable transfection 
efficiency. Spent media and cells were mixed by scraping, and the liquid was frozen for storage. Stable pools of HEK293 cells expressing steroid-modifying genes began with transfection of $\sim 800,000$ cells using the lipofectamine 3000 kit, as above. 48 hours after transfection, cells were selected via $1.5 \mu \mathrm{g} \mathrm{mL}{ }^{-1}$ puromycin (Sigma). After eighteen days, antibiotic was decreased to $0.5 \mu \mathrm{g} \mathrm{mL} \mathrm{m}^{-1}$ puromycin. To modify steroids, stable pool cells were plated at 7,000 cells per $\mathrm{cm}^{2}$ with $40 \mu \mathrm{M}$ of the desired substrate. The cells were incubated for eight days, after which adhered cells were scraped to mix with the media and frozen for storage.

\section{Steroid Product Isolation.}

Liquid-liquid separation with a 3:10 methanol : methyl-tert-butyl ether v/v organic phase removed lipids from the media ${ }^{[17]}$. The media $(2 \mathrm{~mL})$ was extracted twice with solvent $(6.5$ $\mathrm{mL}$ and $3 \mathrm{~mL}$ ), vortexing for three minutes each time. The upper layers were removed, combined, dried down, and resuspended in methanol $(100 \mu \mathrm{L})$. Lipids were analyzed with an Agilent 1200 series HPLC system and 6530 qTOF mass spectrometer. Steroids were separated with a Thermo Scientific Hypersil GOLD C18 column $(1.9 \mu \mathrm{m}, 50 \times 2.1 \mathrm{~mm})$ in an acetonitrile gradient in water with formic acid $(0.1 \% \mathrm{v} / \mathrm{v})^{[18]}$. Known products were compared to standards for quantification. Please refer to the supporting information for HPLC gradients, steroid sources, and chromatograms of steroid products with standards.

\section{Unknown Steroid Purification and NMR.}

Twenty-two T150 flasks of the CYP7B1-expressing cells were used to process substrate $\mathbf{3}$, yielding $440 \mathrm{~mL}$ of media. Sixteen similar flasks were used to process substrate 7, resulting in $320 \mathrm{~mL}$ of media. Liquid-liquid extraction was performed with the same proportions as above, with the addition of a sodium sulfate drying step. The product mixtures from $\mathbf{3}$ and $\mathbf{7}$ were resuspended in 3 and $5 \mathrm{~mL}$ of methanol, respectively. An Agilent 1200 semipreparative HPLC system with a Phenomenex Luna Cl8 column $(5 \mu \mathrm{m}, 250 \times 10 \mathrm{~mm})$ was used to purify the steroid products $\mathbf{4 , 5}$, and $\mathbf{8}$. This resulted in $0.7 \mathrm{mg}$ of $\mathbf{4}, 0.4 \mathrm{mg}$ of $\mathbf{5}$, and $2.2 \mathrm{mg}$ of 8. NMR spectra were obtained in $\mathrm{CD}_{3} \mathrm{OD}$ with a Bruker AVANCE $500 \mathrm{MHz}$ spectrometer equipped with a ${ }^{1} \mathrm{H}\left\{{ }^{13} \mathrm{C} /{ }^{15} \mathrm{~N}\right\}$ cryoprobe and a Bruker AVANCE $500 \mathrm{MHz}$ spectrometer equipped with a ${ }^{13} \mathrm{C} /{ }^{15} \mathrm{~N}\left\{{ }^{1} \mathrm{H}\right\}$ cryoprobe. ${ }^{13} \mathrm{C}$ and ${ }^{1} \mathrm{H}$ shifts and assignments are in Table S2. ${ }^{13} \mathrm{C},{ }^{1} \mathrm{H}$, HSQC, HMBC, COSY, ROESY, and TOCSY spectra, along with HPLC methods, can be found in the supporting information.

\section{Rosetta Steroid Docking Models.}

We generated comparative models for CYP7B1 binding steroids based on crystallized enzymes with Rosetta ${ }^{[44]}$. The algorithm selects for structures with optimal physical interactions, solvent accessible surface area, and bond angles by assigning structures a Rosetta score; lower Rosetta Energy Unit (REU) values suggest more energetically favorable conformations $^{[44]}$. The two solved structures within $30 \%$ sequence identity and $10^{-4}$ BLAST confidence, and bound to chemically similar substrates, were PDB IDs $3 \mathrm{sn} 5$ and $3 \mathrm{v} 8 \mathrm{~d}^{[25]}$. We threaded the sequence of CYP7B1 onto the coordinates of those structures and combined fragments of each to create ten thousand hybrid models of CYP7B $1^{[24,44]}$. The heme was inserted according to the original crystals' bond angles and obabel-derived partial 
charges; this was followed by all-atom optimization ${ }^{[45]} . \sim 2500$ reasonable structures were identified by their Rosetta score falling within fifty REU of the lowest-scoring structure, and were clustered at $3 \AA$ RMSD.

An ensemble of the twenty best-scoring CYP7B1 conformations were used in docking 1, 3, and 7, generating ten thousand binding predictions for each steroid. Typical parameters for these RosettaLigand docking runs were used: the steroid was randomly placed within $5 \AA$ of the binding pocket center, coarsely fit inside, and accommodated by sidechains within 5 $\AA^{[24]}$. Energetically feasible binding modes were identified by their overall Rosetta score within $65 \mathrm{REU}$ of the best mode by overall score (to account for variations between the ensemble models), and their $\Delta \mathrm{G}$-binding analog score within $4 \mathrm{REU}$ of the best mode (analogous to the score contribution of one hydrogen bond). These structures were clustered at $3 \AA$ RMSD between substrate atoms, and the cluster representative was chosen by the lowest $\Delta$ G-binding analog score. This resulted in approximately seventy energetically comparable structures per steroid. As it was not possible to determine the best binding mode by energy alone, other information was incorporated to identify the modes shown. We selected conformations that placed the hydroxylation site within $3.5 \AA$ of the ferryl oxygen, as these are the only modes capable of mediating the observed reactions. We avoided conformations that would require unlikely substrate trajectories into the active site, instead choosing those that resembled the orientations of substrates in the homologous crystals. Thus we produced a binding mode for each hydroxylation mode for each substrate, for a total of four models. Please refer to the supporting information for structure model files and clustering details.

\section{Supplementary Material}

Refer to Web version on PubMed Central for supplementary material.

\section{Acknowledgements}

This work was supported by the Defense Advanced Research Projects Agency HR0011-12-C-0061 and the National Institute of Health P50 GM107618 (Laboratory of Systems Pharmacology) and R01 GM086258 (JC). We are grateful to the ICCB-Longwood Analytical Chemistry Core facility at Harvard Medical School for use of their mass spectrometer. We would also like to thank S. Trauger, K. Chatman, and G. Byrd at the Harvard Small Molecule Mass Spectrometry Core.

\section{References}

1. Kadmiel M, Cidlowski JA, Trends Pharmacol. Sci 2013, 34, 518-530. [PubMed: 23953592]

2. Sarnes E, Crofford L, Watson M, Dennis G, Kan H, Bass D, Clin. Ther 2011, 33, 1413-1432. [PubMed: 21999885]

3. Haendler B, Cleve A, Mol. Cell. Endocrinol 2012, 352, 79-91. [PubMed: 21704118]

4. Mager DE, Moledina N, Jusko WJ, J. Pharm. Sci 2003, 92, 1521-1525. [PubMed: 12820156]

5. Keski-Rahkonen P, Huhtinen K, Poutanen M, Auriola S, J. Steroid Biochem. Mol. Biol 2011, 127, 396-404. [PubMed: 21684334]

6. Huang P, Chandra V, Rastinejad F, Annu. Rev. Physiol 2010, 72, 247-272. [PubMed: 20148675]

7. Pellissier H, Santelli M, Org. Prep. Proced. Int 2001, 33, 1-58.

8. Fernandes P, Cruz A, Angelova B, Pinheiro HM, Cabral JMS, Enzyme Microb. Technol 2003, 32, 688-705. 
9. Swizdor A, Kolek T, Panek A, Milecka N, Curr. Org. Chem 2012, 16, 2551-2582.

10. Nes WD, Chem. Rev 2011, 111, 6423-51. [PubMed: 21902244]

11. Mathew PA, Mason JI, Trant JM, Waterman MR, Mol. Cell. Endocrinol 1990, 73, 73-80. [PubMed: 2292341]

12. Szczebara FM, Chandelier C, Villeret C, Masurel A, Bourot S, Duport C, Blanchard S, Groisillier A, Testet E, Costaglioli P, et al., Nat. Biotechnol 2003, 21, 143-149. [PubMed: 12514739]

13. Parikh A, Gillam EM, Guengerich FP, Nat. Biotechnol 1997, 15, 784-788. [PubMed: 9255795]

14. Gerber A, Milhim M, Hartz P, Zapp J, Bernhardt R, Metab. Eng 2016, 36, 19-27. [PubMed: 26976492]

15. Wriessnegger T, Pichler H, Prog. Lipid Res 2013, 52, 277-293. [PubMed: 23567752]

16. Kabasakalian P, Britt E, Yudis MD, J. Pharm. Sci 1966, 55, 642-642. [PubMed: 5924134]

17. Matyash V, Liebisch G, V Kurzchalia T, Shevchenko A, Schwudke D, J. Lipid Res 2008, 49, 1137-46. [PubMed: 18281723]

18. Surowiec I, Koc M, Antti H, Wikström P, Moritz T, J. Sep. Sci 2011, 34, 2650-2658. [PubMed: 21898811]

19. Stiles AR, McDonald JG, Bauman DR, Russell DW, J. Biol. Chem 2009, 284, 28485-28489. [PubMed: 19687010]

20. Yantsevich AV, Dichenko YV, Mackenzie F, Mukha DV, Baranovsky AV, Gilep AA, Usanov SA, Strushkevich NV, FEBS J 2014, 281, 1700-1713. [PubMed: 24491228]

21. Wang Y, Sun D, Chen Z, Ruan H, Ge W, Biocatal. Biotransformation 2013, 31, 168-174.

22. Schmitz D, Zapp J, Bernhardt R, Microb. Cell Fact 2014, 13, 81. [PubMed: 24903845]

23. Olsen L, Oostenbrink C, Jørgensen FS, Adv. Drug Deliv. Rev 2015, 86, 61-71. [PubMed: 25958010]

24. Combs SA, Deluca SL, Deluca SH, Lemmon GH, Nannemann DP, Nguyen ED, Willis JR, Sheehan JH, Meiler J, Nat. Protoc 2013, 8, 1277-1298. [PubMed: 23744289]

25. Tempel W, Grabovec I, MacKenzie F, Dichenko YV, Usanov SA, Gilep AA, Park H-W, Strushkevich N, J. Lipid Res 2014, 55, 1925-1932. [PubMed: 24927729]

26. Ortiz De Montellano PR, De Voss JJ, Substrate Oxidation by Cytochrome P450 Enzymes, 2005.

27. Wulfson NS, Zaretskii VI, Sadovskaya VL, Semenovsky AV, Smit WA, Kucherov VF, Tetrahedron 1966, 22, 603-614.

28. Andrushina VA, Druzhinina AV, Yaderets VV, Stitsenko TS, Voishvillo NE, Appl. Biochem. Microbiol 2011, 47, 42-48.

29. Schaaf O, Dettner K, J. Steroid Biochem. Mol. Biol 2000, 75, 187-199. [PubMed: 11226835]

30. Schenck GO, Neumuller OA, Eisfeld W, European J. Org. Chem 1958, 579, 202-210.

31. Horn EJ, Rosen BR, Chen Y, Tang J, Chen K, Eastgate MD, Baran PS, Nature 2016, 533, 77-81. [PubMed: 27096371]

32. Shan LH, Liu HM, Huang KX, Dai GF, Cao C, Dong RJ, Bioorganic Med. Chem. Lett 2009, 19, 6637-6639.

33. Choudhary MI, Batool I, Shah SAA, Nawaz SA, Atta-ur-Rahman, Chem. Pharm. Bull. (Tokyo). 2005, 53, 1455-1459. [PubMed: 16272731]

34. Rose K, Allan A, Gauldie S, Stapleton G, Dobbie L, Dott K, Martin C, Wang L, Hedlund E, Seckl JR, et al., J. Biol. Chem 2001, 276, 23937-23944. [PubMed: 11290741]

35. Rose KA, Stapleton G, Dott K, Kieny MP, Best R, Schwarz M, Russell DW, Björkhem I, Seckl J, Lathe R, Proc. Natl. Acad. Sci. U. S. A 1997, 94, 4925-4930. [PubMed: 9144166]

36. Stapleton G, Steel M, Richardson M, Mason JO, Rose KA, Morris RGM, Lathe R, J. Biol. Chem 1995, 270, 29739-29745. [PubMed: 8530364]

37. Yau JLW, Noble J, Graham M, Seckl JR, J. Neurosci 2006, 26, 11034-11040. [PubMed: 17065445]

38. Chung BC, Picado-Leonard J, Haniu M, Bienkowski M, Hall PF, Shively JE, Miller WL, Proc. Natl. Acad. Sci. U. S. A 1987, 84, 407-11. [PubMed: 3025870]

39. Petrunak EM, DeVore NM, Porubsky PR, Scott EE, J. Biol. Chem 2014, 289, 32952-32964. [PubMed: 25301938] 
40. Gonzalez E, Guengerich FP, J. Biol. Chem 2017, 292, 13168-13185. [PubMed: 28684414]

41. Kominami S, Nishida N, Takemori S, Biochim. Biophys. Acta 1996, 1301, 199-206. [PubMed: 8664329]

42. Duport C, Spagnoli R, Degryse E, Pompon D, Nat. Biotechnol 1998, 16, 186-189. [PubMed: 9487528]

43. Kau TR, Schroeder F, Ramaswamy S, Wojciechowski CL, Zhao JJ, Roberts TM, Clardy J, Sellers WR, Silver PA, Cancer Cell 2003, 4, 463-476. [PubMed: 14706338]

44. Song Y, Dimaio F, Wang RYR, Kim D, Miles C, Brunette T, Thompson J, Baker D, Structure 2013, 21, 1735-1742. [PubMed: 24035711]

45. O'Boyle NM, Banck M, James CA, Morley C, Vandermeersch T, Hutchison GR, J. Cheminform 2011, 3, 1-14. [PubMed: 21214931] 


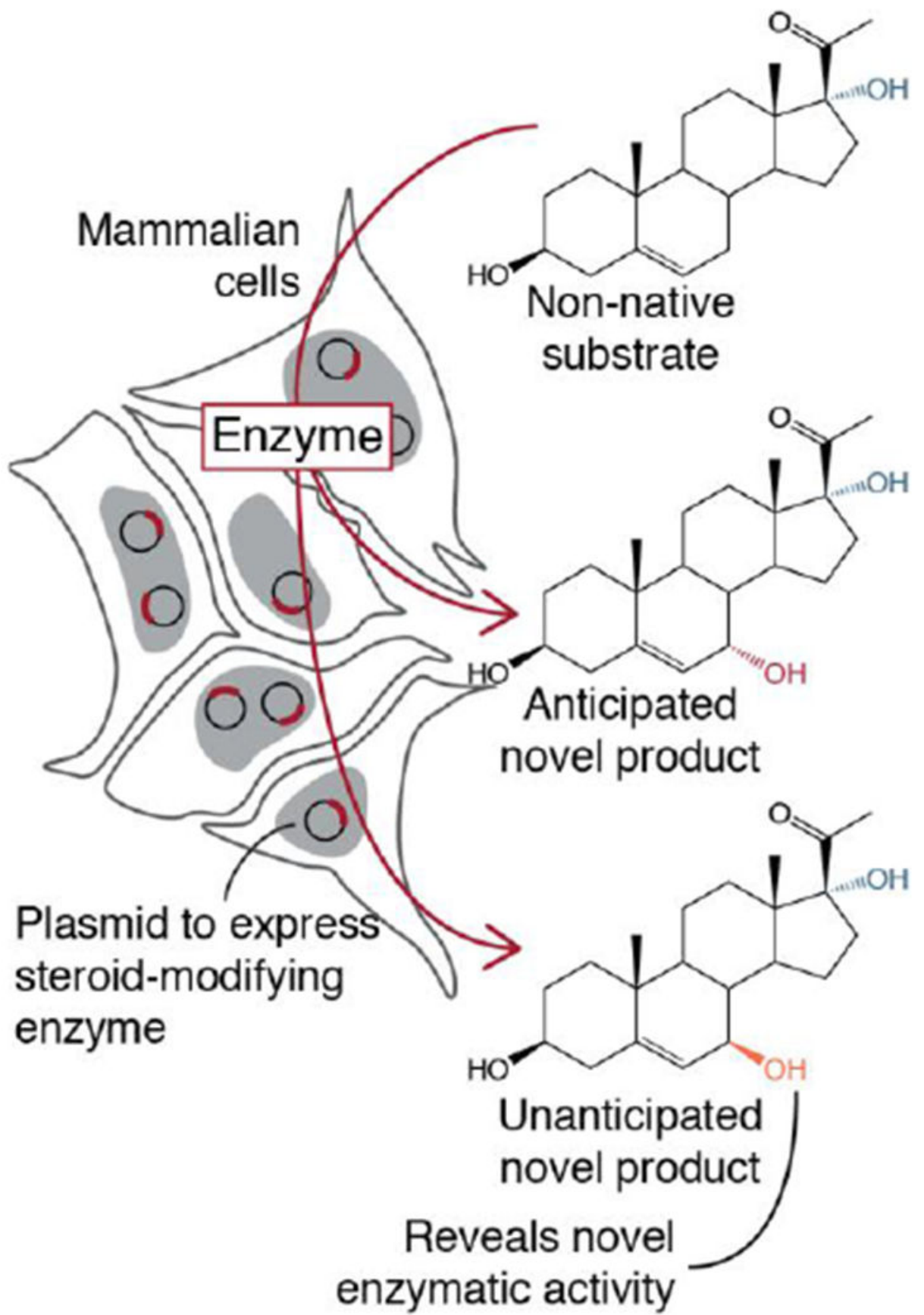

Figure 1.

Overview of our method for novel steroid biosynthesis. Steroid-modifying enzymes are expressed heterologously in mammalian cells and exposed to a non-native substrate, resulting in novel steroid product(s). 
A)

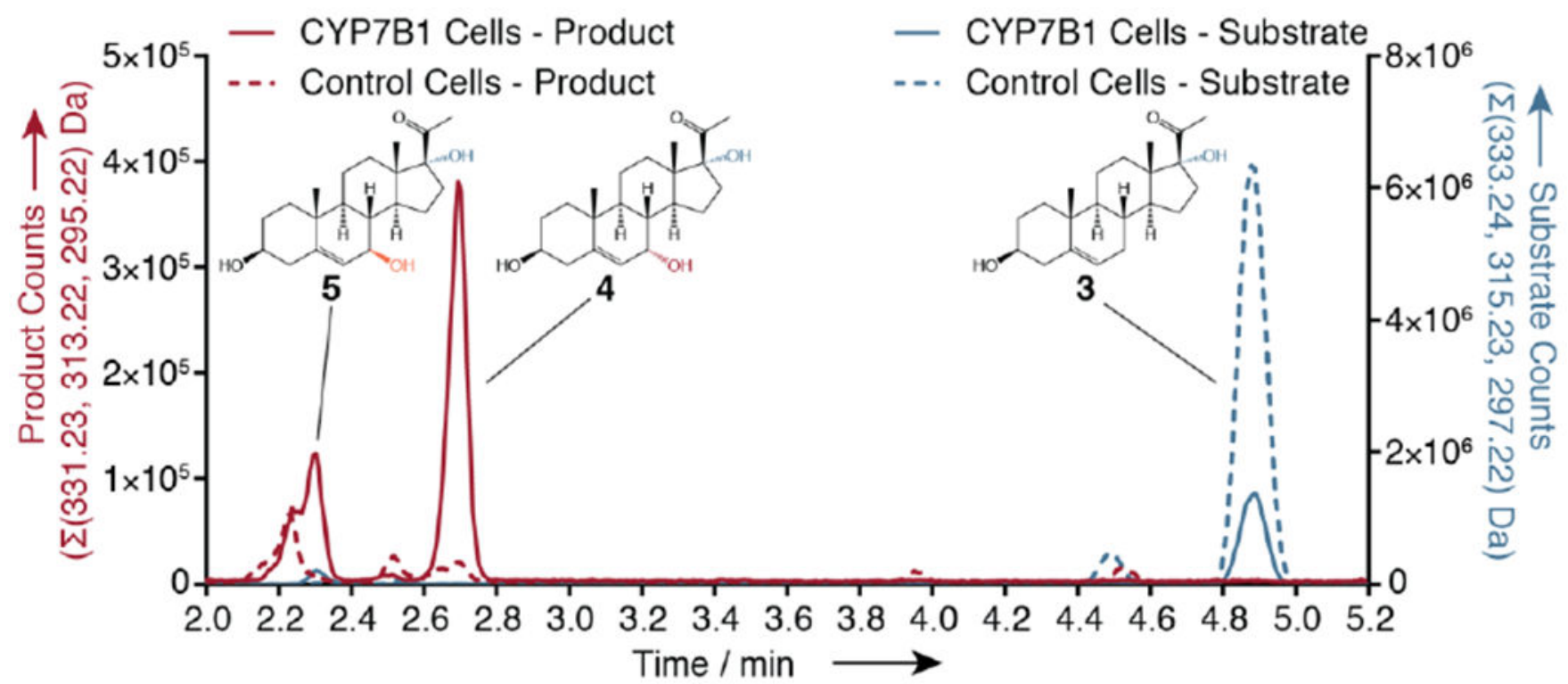

B)

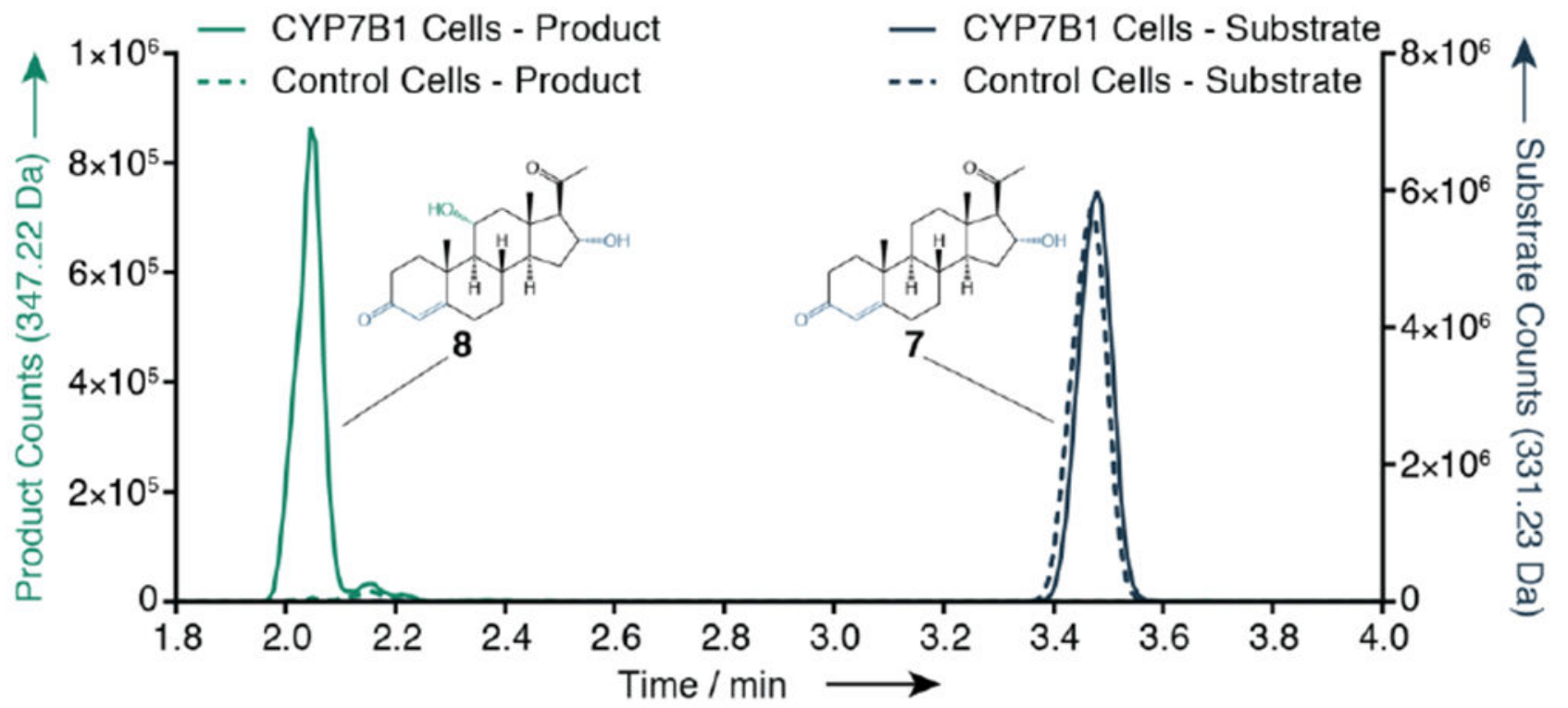

Figure 2.

Extracted ion mass chromatograms comparing products of cells supplied with $\mathbf{3}$ and $\mathbf{7}$.

CYP7B1 cells stably expressed that enzyme, while the negative control cells stably expressed green fluorescent protein. CYP7B1 cell samples were diluted tenfold. A) Only CYP7B1 cells exposed to 3 produced peaks corresponding to the $\left[\mathrm{M}+\mathrm{H}-\mathrm{H}_{2} \mathrm{O}\right]^{+}$, [M $\left.+\mathrm{H}-2 \mathrm{H}_{2} \mathrm{O}\right]^{+}$, and $\left[\mathrm{M}+\mathrm{H}-3 \mathrm{H}_{2} \mathrm{O}\right]^{+}$ions of 4 and 5. B) Only CYP7B1 cells exposed to 7 produced a single peak corresponding to the $[\mathrm{M}+\mathrm{H}]_{+}$ion of $\mathbf{8}$. 
A)

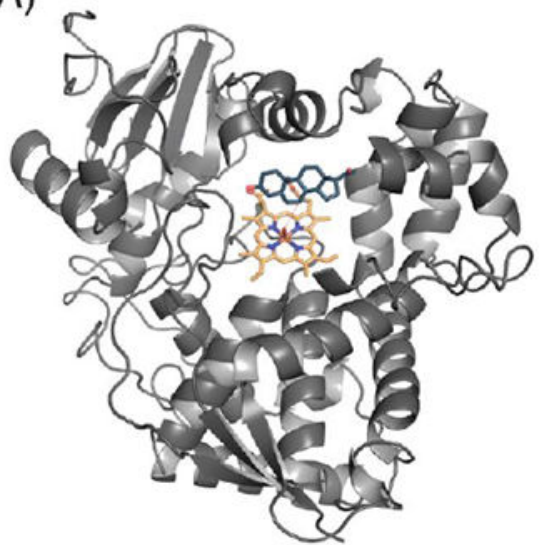

C)

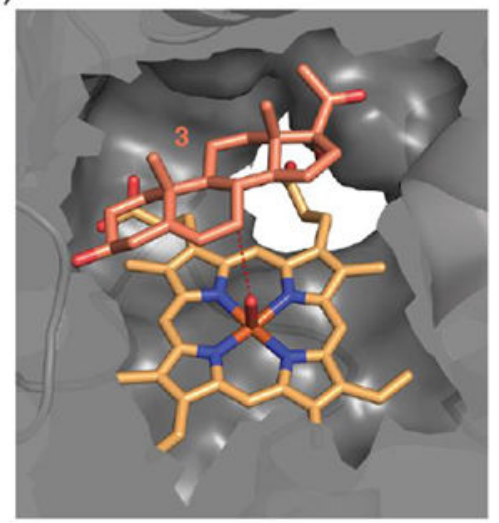

E)

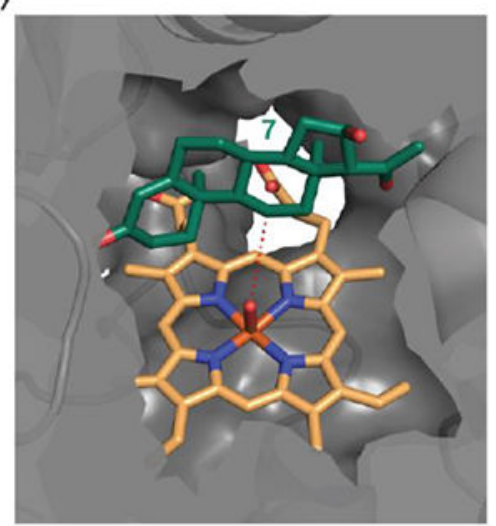

B)

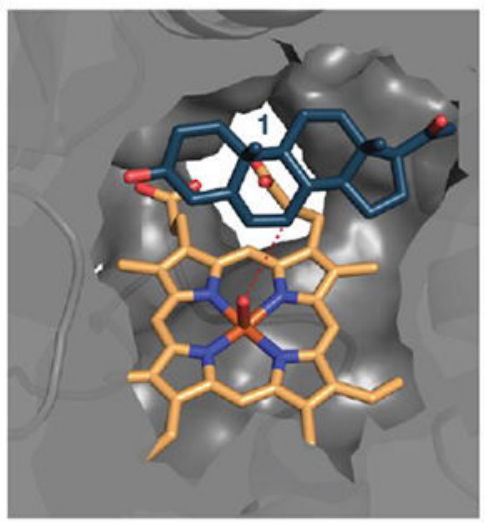

D)

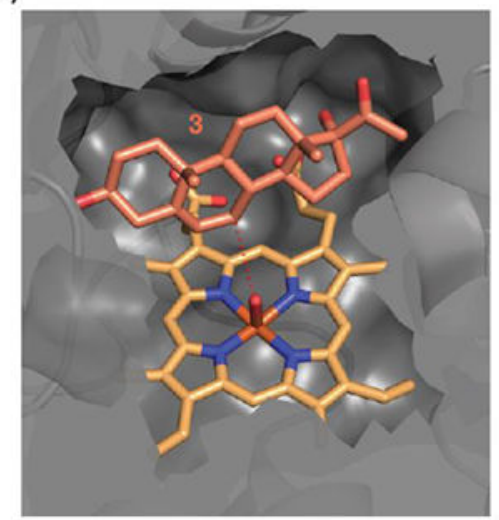

F)

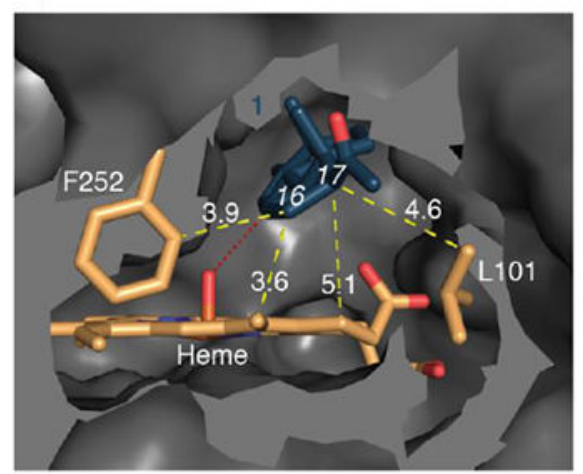

Figure 3.

Predicted structures of the CYP7B1 active site with steroid substrates $\mathbf{1}$ (blue), $\mathbf{3}$ (orange), and 7 (green). A) Cartoon representation of holo-CYP7B1 with 1. B-E) Structural models of CYP7B1 permitting 7a-hydroxylation of $\mathbf{1}$ (B) and $\mathbf{3}$ (C), 7 $\beta$-hydroxylation of $\mathbf{3}(\mathrm{D})$, and 11a-hydroxylation of 7 (E). The red dashed line highlights the positions of the reactive ferryl oxygen and the observed hydroxylation site. F) Side view of native substrate $\mathbf{1}$ in active site. Yellow dashed lines indicate the proximity of steroid carbons C-16 and C-17 to the edge of the binding pocket. Distances are in Angstroms. 


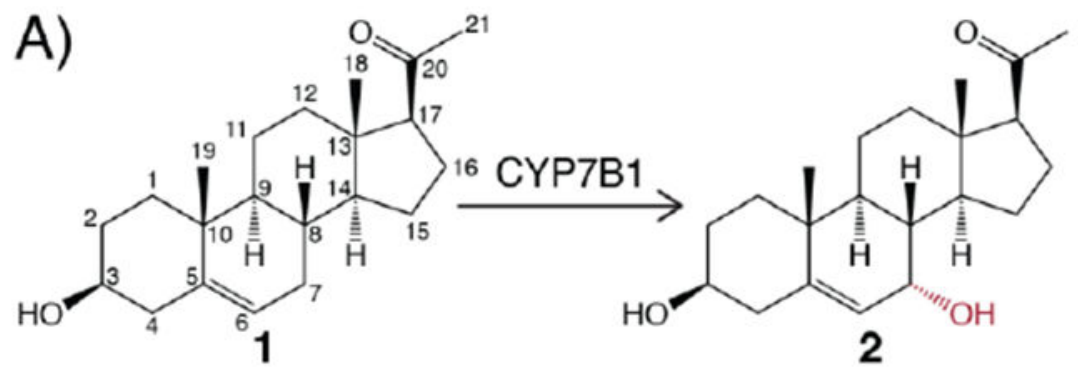

\begin{tabular}{|l|l|}
\hline $\begin{array}{l}\text { Expression } \\
\text { Condition }\end{array}$ & $\begin{array}{l}\text { 2 Yield } \\
\left(\boldsymbol{\mu} \mathrm{mL}^{-1}\right)\end{array}$ \\
\hline Transient & $1.4 \pm 0.3$ \\
\hline Stable & $4.6 \pm 0.7$ \\
\hline
\end{tabular}

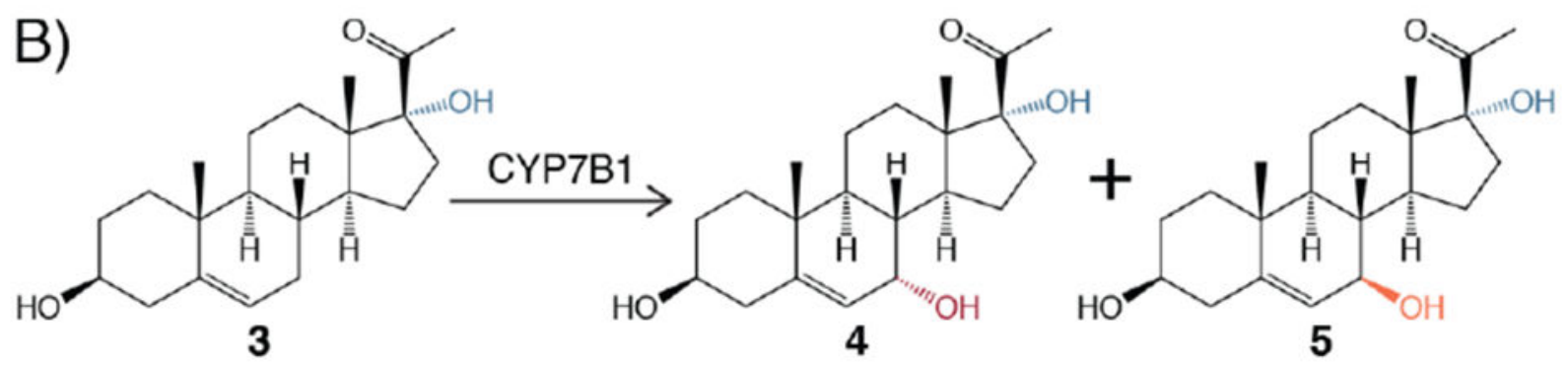

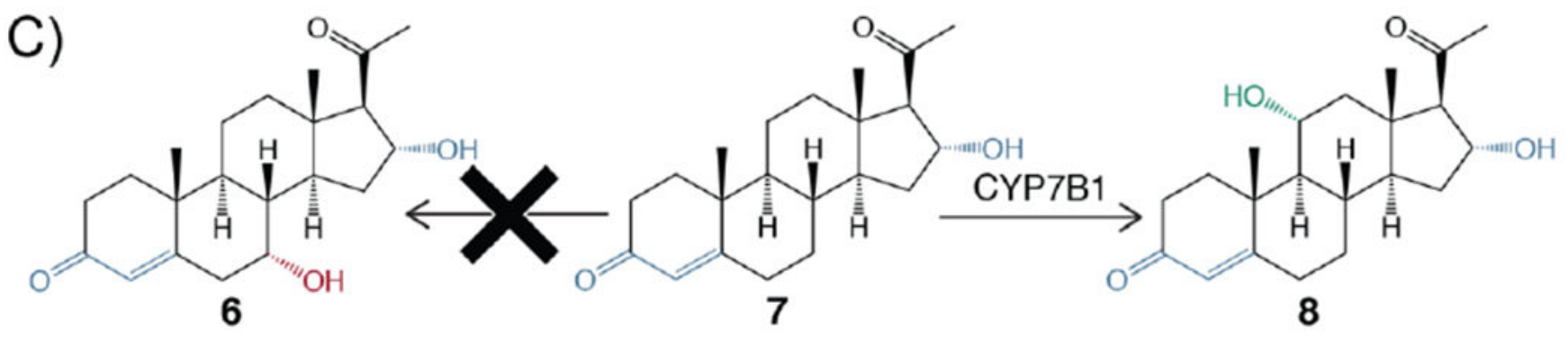

Scheme 1.

Steroid-modifying reactions observed from CYP7B1. A) CYP7B1 hydroxylates native substrate pregnenolone (1) to form 7a-hydroxypregnenolone (2). Yield is in $\mu \mathrm{g}$ of steroid per $\mathrm{mL}$ of media extracted. B) CYP7B1 hydroxylates non-native substrate 17ahydroxypregnenolone (3) to form novel product isomers 7a,17a-dihydroxypregnenolone (4) and 7 $\beta, 17 a$-dihydroxypregnenolone (5). C) CYP7B1 hydroxylates non-native substrate 16a-hydroxyprogesterone (7) to form 11a,16a-dihydroxyprogesterone (8). The anticipated product 7a,16a-dihydroxyprogesterone (6) was not observed. 